\title{
Municípios e Educação
}

Justino Magalhães

1. No decurso do período moderno e com maior incidência no período contemporâneo, na sequência das revoluções liberais e republicanas e no quadro dos regimes democráticos actuais, os municípios constituíram e constituem instância de representação e desenvolvimento. São formados por população, território, poder administrativo e capacidade económico-financeira. Comportam poder de decisão. No campo da educação, são instâncias com legitimidade meta-educativa, nomeadamente em matéria de costumes, cidadania, consulta e decisão, oferta escolar. São constitutivos da memória colectiva e de identidade social e individual.

Este Dossier temático da Revista Sarmiento incide sobre Municípios e Educação, numa perspectiva histórico-pedagógica, transversal a diferentes países, mas centrada no município, associado aos planos local e regional. Nasce deste olhar uma universalidade proporcionada pelos Estados-Nação na construção do Ocidente Escolar. Mas a observação focada nos locais e nas regiões, representados pelos municípios em Portugal, Brasil, Espanha revela sensibilidades próprias. O lugar destinado aos Municípios não foi uniforme, nem uniformes terão sido a tónica e o tempo de intervenção. Há todavia uma linha de diagnóstico, reconhecimento das necessidades, e um sentido estratégico das políticas de modernização, de que os municípios fizeram parte. Em todos os locais observados, houve iniciativas municipais e estas não foram só uma questão de segmento do ensino, ou de estratos sócio-culturais e menos uma questão geográfica. A instância local, ou seja o município foi parte do plano de desenvolvimento, em qualquer dos territórios em observação.

Esta abordagem respeita os seguintes eixos epistémicos: o município como unidade histórico-pedagógica, complexa e multidimensional; os municípios como constitutivos dos Estados-Nação; os municípios como instância de meta-educação, ideando, decidindo e sustentando projectos desenvolvimentistas e autonómicos. Tais manifestações fizeram-se sentir com relevância na oferta escolar, na formação profissional, na escolarização de públicos específicos, enfim na adequação dos currículos nacionais às realidades locais. Este Dossier temático pretende dar a conhecer, no plano histórico-pedagógico, a acção dos Municípios na Educação e na Escolarização, apresentando estudos de caso e permitindo uma perspectiva transversal, porventura comparativa sobre o Municipalismo na Educação, num quadro geográfico alargado.

2. O Dossier Municípios e Educação é composto por nove estudos que revelam, ilustram e documentam uma complementaridade na causa da educação e na amplitude da 
influência municipalista. A apresentação dos textos, segundo a ordem temporal, favorece a transversalidade e a unidade temática e histórica do municipalismo na educação e na cultura. Em consequência, a primeira surpresa é a diversidade geográfica entre os casos observados: quatro em Portugal, dois no Brasil, três em Espanha. Notório é também 0 tempo-longo da observação - de final do período moderno, coincidindo com as principais transformações que conduziram à decadência do Antigo Regime e do Regime Colonial, até à autonomia e à democracia municipais das décadas recentes. Os municípios intervieram em matérias distintas. Não o fizeram de modo uniforme, mas houve comunalidades no modo de acção e há temporalidades que se replicam. Tomar os municípios como unidade histórico-pedagógica é também integrá-los nos planos local, regional, nacional, transnacional, de que ressaltam quer o tranversal, quer o singular.

Em As Vilas na América portuguesa e a emergência da escola pública: (séculos XVIII e XIX), Thais Nívia de Lima e Fonseca, da Universidade Federal de Minas Gerais, Brasil, retoma estudos que tem vindo a realizar para Minas Gerais. Com a exploração do ouro, a partir da última década do século XVII, a região de Minas beneficiou de uma acelerada urbanização. Ao longo do século XVIII, foram implantadas 14 vilas, com estatuto de municípios, dispondo de Câmaras de Vereadores. A modernização do mundo rural foi mais lenta e prolongou-se pelo século XIX, sendo acompanhada da municipalização. Até 1889, foram criados mais de 95 municípios. Thais Fonseca faz uma breve síntese histórica sobre a Reforma Pombalina da Instrução, com particular incidência na região de Minas Gerais. Das 44 cadeiras criadas em diferentes capitanias, 7 foram criadas nas principais vilas de Minas Gerais: 4 de Primeiras Letras (nas vilas de Sabará, Vila Rica, São João del Rei e na Cidade de Mariana) e 3 de Gramática Latina (nas vilas de São João del Rei, Vila Rica e na Cidade de Mariana). Assinala a autora que, nas décadas seguintes e dando satisfação a demandas apresentadas pelas autoridades locais, foram criadas outras cadeiras. Em 1814, havia registo de 46 cadeiras na Capitania, 34 de Primeiras Letras e 12 de Gramática. Algumas Câmaras tinham estabelecido mestres de primeiras letras, mas a prática mais habitual, entre as famílias dos segmentos médios da população e das elites locais, era 0 recurso a mestres particulares. Com efeito, nas décadas finais do século XVIII, observase uma expansão da rede de Cadeiras de Primeiras Letras, nomeadamente nas vilas mais populosas. A questão da instrução, que não deixou de estar associada ao Subsídio Literário, foi um dos assuntos mais polémicos na relação entre as autoridades locais e 0 poder central. Mas, como conclui Thais Fonseca, a instrução e o desenvolvimento cultural haviam-se tornado condição de modernização e prerrogativa fundamental para as populações dos centros urbanos.

O estudo As Escolas do Esino Primário em Lisboa e no Interior de Portugal, no limiar da descentralização oitocentista, da autoria de Áurea Adão, do Instituto de Educação da Universidade de Lisboa, mostra como, em resultado das orientações centrais e das orientações municipalistas, houve, nomeadamente a partir do último quartel do século XIX, aspectos comuns entre o município de Lisboa, capital do País, e o município de Proençaa-Nova, no Interior de Portugal. Mas este estudo revela também que a municipalização não foi uniforme, reflectindo as dimensões geeográfica e sociocultural, e correspondendo 
a dinâmicas administrativas de proximidade, nas quais os poderes e as elites locais se envolveram de modo igualmente diferenciado.

Em Luta pela Instrução e Disputas Políticas em Portugal, na segunda Metade do Século XIX. A Escola para meninas na Freguesia de São Vicente de Pereira do Município de Ovar, Wenceslau Gonçalves Neto e Justino Magalhães, da Universidade de Uberaba/ Universidade Federal de Uberlândia (Brasil) e do Instituto de Educação da Universidade de Lisboa, apresentam um caso em que a iniciativa particular, pode ter sido preterida, ou pelo menos adiada, em face de políticas municipalistas, inseridas no plano de desenvolvimento escolar. O caso reporta a Ovar, município do litoral português e documenta as iniciativas empreendidas por um empresário local que fizera fortuna no Brasil. Regressado a Ovar, esse industrial disponibilizou terreno e uma verba para a construção de uma escola para o ensino de meninas. Para os autores do artigo, esta iniciativa integra-se num movimento mais amplo de beneficiência e filantropia, em que mereceu destaque a legado Conde Ferreira (1866), pois que foi extensivo ao todo nacional. Analisados os factos a partir do município de Ovar, os autores mostram como os regulamentos e os planos de desenvolvimento local também estavam dependentes de forças e orientações políticas, não necessariamente convergentes.

No texto Los Municipios andaluces y la educación, la aplicación de la legislación durante el siglo XIX, Ana-Maria Montero-Pedrera, da Facultad de Ciencias de la Educación, Universidad de Sevilla, apresenta uma evolução sobre o ensino na Andaluzia do século XIX. Era uma região agrícola onde a instrução avançou de forma lenta. Nesse processo, os municípios estiveram envolvidos, em consonância com as principais Reformas da Instrução. Ao longo do século XIX, a população urbana não cessou de crescer, enquanto, por outro lado, se acentuava o despovoamento de algumas zonas rurais. Ana Maria MonteroPedrera apresenta um resumo das principais leis para o ensino e destina a segunda parte do artigo à organização do ensino, nos municípios de Andaluzia. De acordo com a lei de 1838, cada município dispunha de uma Comisión Local de Instrucción Primaria. Com a lei de 1857, aquelas Comissões passaram a ser denominadas Juntas Locales de Instrucción Pública. Na segunda metade do século XIX, as comissões ou juntas locais de instrução primária foram-se afirmando nas cidades e nos municípios. Ainda que, de modo lento, a alfabetização progrediu e nessa evolução merecem destaque os organismos municipais.

No mesmo sentido, de conciliar as políticas educativas com o desenvolvimento cultural e social, ressalta o estudo Estratégias políticas e administrativas na Assistência de Menores Desvalidos no município de Pelotas/ RS, Brasil (1889-1930): primeiras aproximações. Este artigo é da autoria de Jeane dos Santos Caldeiras e Giana Lange do Amaral, do Departamento de Fundamentos da Educação - PPGE - FaE/UFPel, bem como de Fernando Ripe, da Universidade Federal de Pelotas. Os autores salientam as políticas do município de Pelotas na instrução, assistência e educação de Menores Desvalidos. Na segunda metade do século XIX, tiveram lugar várias alterações na sensibilidade e na caracterização de segmentos infantis e juvenis marginalizados, devido a situações de probreza, abandono e delinquência. No Brasil, com a implantação da Primeira República, os municípios 
foram chamados a intervir nessa matéria. A melhoria das condições de assistência e de educação, eram também medidas assistenciais de controle e de vigilância sobre as condições de abandono moral e físico da infância desvalida. Tais medidas eram essenciais para manter a idealização social de ordem e paz. Entre finais do século XIX e os anos 30 do século XX, o município de Pelotas levou a cabo acções de tipo diverso, com vista à escolarização e institucionalização das populações carenciadas. Enquanto realizava a "limpeza" do perímetro urbano, através da eliminação de zonas de prostituição e de habitações populares, tais como vilas, pátios, cortiços e corredores localizados no centro da cidade, a municipalidade procedeu a um plano de educação, nomeadamente nas partes nobres da cidade. Desde início do século que a municipalidade contava com a acção, de diverso tipo, de Asilos. As políticas republicanas beneficiaram da acção da Igrega Católica.

Higienismo e Municipalismo no Porto (1900-1926), da autoria de Luís Alberto Marques Alves, da Faculdade de Letras da Universidade do Porto/ Centro de Investigação Transdisciplinar Cultura Espaço e Memória, e de Francisco Diogo Mota Soares Pereira, da Faculdade de Letras da Universidade do Porto/Bolseiro do Projeto INOVAR, é um texto em que as virtualidades dos estudos municipalistas fazem ressaltar diferentes aspectos, em simultâneo. De modo análogo ao quadro descrito no texto anterior, um desses aspectos é a importância da geografia como demarcação e caracterização de um território educativo e de desenvolvimento social, onde as políticas locais foram orientadas para um plano integrado. Com efeito, a melhoria das condições urbanísticas era condição para a melhoria da saúde e da higiene, e esta melhoria estava associada a melhorias na aculturação escrita. Foi em contexto escolar que o movimento médico e as políticas higienistas, com particular relevo para a acção de Ricardo Jorge, médico e filantropo, encontraram uma coerência e uma linha de desenvolvimento irreversíveis. Concluem os autores que, apesar da contenção orçamental, houve um grande empenho do município do Porto e dos seus agentes, para traçarem um novo rumo na política educativa. 0 domínio educativo-sanitário foi associado à escolarização e permitiu uma aproximação à pedagogia moderna.

O artigo El Papel de los Municipios en la Expansión de la Red de Edificios Escolares Públicos en España, 1920-1937, da autoria de María del Pilar García Salmerón, do Colegio Público Fuente del Oro, Cuenca, España, apresenta uma evolução da rede espanhola e mostra que essa evolução envolveu os municípios. Até às primeiras décadas do século $\mathrm{XX}$, a rede escolar tinha sido fundamentalmente assegurada pelos municípios. Os sucessivos governos centrais limitavam-se a estabelecer a normativa a que deveria obedecer 0 funcionamento geral, mas não disponibilizavam fundos necessários para que as entidades locais pudessem cumprir o que thes era acometido. Em 1920, foi criado un organismo regulador para a qualidade e a idoneidade dos novos edifícios escolares. Foi a Oficina Técnica para Construcción de Escuelas que tinha associado um plano de construções a que os municípios poderiam candidatar-se. $\mathrm{O}$ crescimento da rede foi exponencial. "La nueva escuela representaría dentro del patrimonio local una pieza emblemática, quizá la más moderna y práctica, dentro de las que originaban y resaltaban el indiscutible orgullo local." A partir da década de vinte, o Estado espanhol ficou mais envolvido na construção de escolas, sempre com a colaboração dos municípios, instituições responsáveis por dar 
início aos trâmites para implantação de um novo edifício escolar, designadamente assegurando a disponibilização de terreno. A participação dos municípios foi decisiva para a expansão escolar.

A educación, compromiso e responsabilidade dos concellos democráticos en Galicia (1978-2018) é o último texto desta série temática. Os autores Hector Pose Porto, da Universidade da Coruña e José Antonio Caride Gómez, da universidade de Santiago de Compostela apresentam um estudo sobre os municipios da Galiza desde o final do Franquismo até a actualidade. A linha principal do trabalho radica no eixo pedagogia social-democracia local, apresentado nos planos diacrónico e sincrónico e como parte do complexo teóricoconceptual e histórico formado por: municipios, administração local, pedagogia social, educação, cidadania. Os autores mostram como o municipalismo das últimas décadas se inscreve em quadros de desenvolvimento locais e regionais de longa duração, que beneficiaram com a democratização e não deixaram de reagir à globalização. Apresentam e analisam os sucessivos quadros legais. Sistematizam e caracterizam as principais acções, projectos, movimentos, mostrando inclusive como os enunciados de tais iniciativas pode induzir a uma expectiva não comprovada. Legitimados pela investigação teórico-experimental a partir do espaço académico e inferindo potencialidades e expectativas a partir dos quadros convencionais e legais, trazem uma visão crítica e de inquiteação face ao que poderia ser efectivamente realizado. As três principais linhas da acção municipal e das cidades-educadoras são "actuaçoes promovidas en relação ao sistema educativo e aos centros escolares"; esforços realizados com a vontade de sobrepôr-se e/ou compensar deficiências ou lacunas no sistema educativo, fundamentalmente no ensino obrigatório; "educação não-formal". Para os autores será possível levar mais longe a democratização do local apoiada numa pedagogia social.

O texto Património Educativo edificado Gaiense - um primeiro ensaio de sistematização da autoria de Ana Vaz (Centro de Trabalho: Câmara Municipal de Vila Nova de Gaia); Eva Baptista (Centro de Trabalho: CITCEM - Centro de Investigação Transdisciplinar Cultura, Espaço e Memória); José António Martin Moreno Afonso (Centro de Trabalho: Instituto de Educação (IE) / Centro de Investigação em Educação (CIEd), da Universidade do Minho, contém uma sistematização dos estudos sobre municípios e apresenta uma perspectiva alongada no tempo sobre o município de Gaia. Traz por fim um inventário das construções escolares naquele município, que apresenta um património escolar, onde a iniciativa particular foi muito frequente. É um património cuja estética reflecte a combinação entre a sensibilidade dos beneméritos e as características da topografia local. O estudo apresentado também permite conhecer a relação entre aculturação escrita e modernização e comprova que a história da escola reflecte as dinâmicas locais e os eixos intermunicipais de desenvolvimento económico e sociocultural.

3. O campo da educação é vasto e a constituição do educacional como objecto histórico integra distintos domínios científicos; cruza com distintos objectos epistémicos. A história do municipalismo e, particularmente, a história dos municípios na educação constitui um campo inovador na historiografia, na representação, no significado para a história 
da educação. Possibilita aceder de modo transversal a distintos quadros geográficos e, de modo interdisciplinar, a realidades singulares, inseridas em movimentos transversais. Tomando o município como local educativo e unidade de observação, emergem novos modos de representar, significar, adensar e projectar a educação na modernidade.

O dossier Municípios e Educação, que aqui se publica, reporta a diferentes geografias e diferentes conjunturas. Apresenta linhas de uniformidade e conformidade, mas também linhas de autonomia e afirmação do regional e do local. Os textos configuram distintas facetas do municipalismo. O município surge configurado como instância de implantação, identidade e desenvolvimento histórico, no estudo sobre Minas Gerais; surge como instância de desenvolvimento, mediando entre o centro, o regional e o local, nos estudos sobre os municípios espanhóis e sobre os municípios do Interior de Portugal; emerge como local e instância de planificação e ideação, actuando na educação formal e junto de públicos que carecem de uma resposta específica, nos estudos sobre os municípios de Lisboa, Porto, Pelotas, ou mais recentemente dos municípios da Galiza; por fim, tomando como referência o estudo sobre o município de Gaia, comprova-se, uma vez mais, que o município comporta uma identidade e que o legado histórico é um meio de cidadania.

Como decorre da leitura dos diferentes estudos aqui apresentados, Municípios e Educação mais do que um tema ou um objecto epistémico, formam um complexo históricopedagógico onde a educação foi possível e se traduziu no destino das comunidades humanas, congregadas, organizadas e orientadas para a resolução do presente e a melhoria em termos de futuro. Mas a leitura sequenciada destes textos possibilita também reconhecer um historicismo inerente ao binómio municípios-educação, que se traduz em permanências e recorrências, mas também em desenvolvimento e progresso, quer associadas ao efeito de modernização e contemporaneidade, quer em função das matérias, das convenções, das políticas de integração e participação cívicas, enfim como democratização.

Ao aceitar o dossier temático Municípios e Educação, que congrega o transversal, entre diferentes tempos históricos e diferentes Estados-Nação, bem assim como o regional e o local, aqui tomados na acepção de municípios e de municipalismo, a Revista Sarmiento está seguramente a afirmar um estatuto próprio no universo dos periódicos científicos em História da Educação. Os municípios tiveram um papel fundamental na educação moderna e contemporânea, intervindo na representação histórica, no ensino, na assistência. $O$ estudo dos municípios possibilita a revisão dos quadros histórico-pedagógicos mais gerais, adensando, cruzando e reorientando o sentido da história. Emergem, deste modo, ciclos histórico-pedagógicos de desenvolvimento que congregam, entre outras, as dimensões geográfica, urbanística, temporal, sociocultural, escolar, assistencial, cívica e de humanização.

Lisboa, 31 de Maio de 2019 